\title{
A REVIEW ON PYROLYSIS OF DIFFERENT TYPES OF PLASTICS
}

\author{
Muhammed Khais $A^{1}$, G. M. Joselin Herbert ${ }^{2}$ \\ ${ }^{1}$ PG Student of Thermal Engineering at Noorul Islam Centre For Higher Education, Thuckalay, Tamil \\ Nadu, India. \\ ${ }^{2}$ Professor, Department of Mechanical Engineering, Noorul Islam Centre for Higher Education, Thuckalay, \\ Tamil Nadu, India
}

\begin{abstract}
Plastics are one of the major inventions of the modern era. It can be molded into different shapes and sizes on the basis of requirement. We cannot think of a life without plastic. The major component of making plastic is crude oil which is non-renewable resource. According to studies the crude oil consumption rate is increasing day by day and it is depleting considerably. The important disadvantage of plastics is treatment of plastic after consumption .Plastic contributes to major portion of municipal waste all over the world. Plastics are non-biodegradable substances which mean It will not undergo normal decomposition as biological matter. So plastic cannot be dumped into landfills or to water bodies. In the case of landfills, plastics will stay there without decomposing and ultimately leads to infertility of soil. And in the case of water bodies, the aquatic organisms eat these plastics misunderstanding as food and it will not digest in their stomach and as a result they dies. Major share of ocean pollution are deposition of post consumed plastics. Manufacturing as well as incineration of plastics causes air pollution which involves production dioxins and leads to deadly diseases like cancer, lung problems...Pyrolysis is a thermochemical decomposition of organic substances at elevated temperatures without the presence of oxygen and it involves phase change as well as chemical composition changes. Municipal waste composes of different types of plastics. In this study we analyze oil extraction from different types of plastics.
\end{abstract}

\section{INTRODUCTION}

Ever since the energy consumption increased researchers have been looking for alternate fuel methods. There are different sources of energy .Of which the most utilized energy is crude oil. According to British Petroleum, the rate of consumption of crude oil is increasing day by day and consumption will be double by 2030.Pyrolysis is opted as the best method for retrieval for energy recovery from post consumed plastics. Municipal waste contains different kinds of plastics such as PET, PS, PE,PP, ... The oil extraction rate of these plastics are different because of their chemical composition. Plastics are manufactured by the process of polymerization in which simple chain monomers are combined to form long chain polymers. In pyrolysis reversal of polymerization is taking place normally called as cracking in which longer chains of polymers are broken down into smaller chain of monomers. On heating plastics without the presence of oxygen produces gas and these gases can be condensed to get liquid oil. Experimental studies show that the liquid oil obtained shows similar properties of diesel and gasoline. The main factors affecting the product quality of the process are temperature, residence time, type of reactor, condensation, presence of catalyst...Studies shows oil obtained from pyrolysis of municipal solid wastes have potential calorific values. Pyrolysis produces three main products such as char, liquidoil, and gas. Properties of these products can be analyzed using Scanning Electron Microscope(SEM), Fourier-transform infrared spectroscopy (FTIR) Gas Chromatographs (GC) and calorimeter.
The aim of this study is to analyze liquid oil obtained from pyrolysis of various type of plastic.

Table 1: Physico-chemical properties of standard gasoline and diesel

\begin{tabular}{|l|l|l|}
\hline Parameter & Gasoline & Diesel \\
\hline Density @ $15^{\circ} \mathrm{C} \mathrm{g} / \mathrm{cm} 3$ & 0.780 & 0.807 \\
\hline $\begin{array}{l}\text { Kinematic Viscosity @ } 40{ }^{\circ} \mathrm{C} \\
(\mathrm{mm} 2 / \mathrm{s})\end{array}$ & 1.17 & $1.9-4.1$ \\
\hline Calorific value $(\mathrm{MJ} / \mathrm{kg})$ & 42.5 & 43 \\
\hline Cetane number & - & $<40$ \\
\hline Octane Number & $81-85$ & - \\
\hline Flash Point $\left({ }^{\circ} \mathrm{C}\right)$ & 42 & 52 \\
\hline Diesel index & - & 40 \\
\hline
\end{tabular}

\section{PRODUCT ANALYSIS OF DIFFERENT}

\section{PLASTICS}

PET is one of the most widely used plastic nowadays. It is a thermoplastic resin and its common applications are in making of water bottles, prepaid cards, atm cards, films, tapes...It is produced by the process of polymerization of ethylene glycol and terephthalic acid. It is the repeated units of ethylene terephthalate $(\mathrm{C} 10 \mathrm{H} 8 \mathrm{O} 4)$ monomer. It is marked as type 1 for identification. The melting point of PET is 250$260{ }^{\circ}$ Cand the density is $1.4 \mathrm{~g} / \mathrm{cm} 3$. According to Toshiaki Yoshioka et.al [1]used prepaid cards as PET for the 
experiment and found out that pyrolysis of pet will give only a small fraction of liquid oil. Catalyst used was calcium hydroxide. The results show that more percentage of gas is obtained than liquid. Only $2 \%$ of liquid oil is obtained from PET pyrolysis. Major fractions were solid, char and gas. Derivatives of benzene and naphthalene obtained as gaseous products. The temperature range is in between 510 to 730 ${ }^{0} \mathrm{C}$. As the temperature increased the oxygen as well as the char content decreased in the reactor. The main gas components obtained were $\mathrm{CO}_{2}$ and $\mathrm{CO}$. They used a fluidized bed reactor rather than a conventional fixed bed reactor due the efficient heat and mass transfer rate. The results clearly suggest that pyrolysis of PET is suitable for obtaining gaseous products and it is not suggested for obtaining liquid oil.

On the other hand Moinuddinsarkar et.al [2] used a fixed bed reactor and calcium hydroxide as catalyst. The catalyst helps to increase the rate of degradation of PET polymer. The temperature was in the range of $400-500{ }^{\circ} \mathrm{C}$. The weight ratio of catalyst to Pet sample was $2: 1$. Hydrocarbon lengths of PET oil obtained were $\mathrm{C}_{6}-\mathrm{C}_{27}$. With the help of differential scanning calorimeter the boiling point of obtained fuel were $65.96^{\circ}$ C.Density of the oil was $0.90 \mathrm{~g} / \mathrm{L}$.

HDPE is one of the highest consumed plastics in the world. It has a linear chain structure with short branches and has a crystalline structure which improves its density as well its strength. Due to the increased strength of HDPE it has wide range of applications such as water drums, milk bottles, fuel tank of automobiles. Due to high chemical resistance of hdpe it is largely used for storage of chemicals for factories and chemical feedstock.

Imtiazahamadet. al [3] have explored the potential use in HDPE pyrolysis at different temperatures. At $250^{\circ} \mathrm{C}$ no product were obtained and as the temperature further increased a linear conversion of HDPE were observed. By reaching $300{ }^{\circ} \mathrm{C}, 60 \%$ of conversion observed. At $350{ }^{\circ} \mathrm{C}$ it was able to convert $98 \%$ of HDPE. Of which $80.88 \%$ were liquid. Increasing temperature further caused a low yield. This is due to the fact that increasing the temperature causes the formation of coke by recombination of cracking fragments. Influence of temperature is directly proportional from $250-300{ }^{0} \mathrm{C}$ and inversely proportional from 350-400 ${ }^{0}$ C.Miskolczi et al., (2004) [4] analyzed the liquid product using FTIR and GC-MS, it was able to know that the carbon chain length is in between 6 and 16. The heating value determined as $30.6 \mathrm{MJ} / \mathrm{Kg}$. The density of lump HDPE oil analyzed as $0.89 \mathrm{~g} / \mathrm{cm} 3$. This means the liquid oil has the similar hydrocarbon structure, calorific value and density as gasoline and diesel. Ding et al...(1997) [5]used an autoclave reactor at $435^{\circ} \mathrm{C}$ for $60 \mathrm{~min}$ with stirrer speed 800 rpm using nitrogen as fluidizing gas for HDPE pyrolysis and obtained an oil yield of $87.2 \mathrm{wt} \%$ without the use of catalyst. With 2\% HZSM-5 as catalyst the oil yield reduced to 82.1 $\mathrm{wt} \%$ and the solid residue remained in the reactor also decreased considerably from $5.5 \mathrm{wt} \%$ to $1.4 \mathrm{wt} \%$, but the gas yield increased to $16.5 \mathrm{wt} \%$. The highest oil yield obtained while using $3 \% \mathrm{TiCl}_{3}$ as catalyst and obtained oil yield of $88.6 \mathrm{wt} \%$.

Bagri and Williams et al (2002) [6] studied the pyrolysis of LDPE using a fixed bed reactor at different temperatures at a heating rate of $10^{\circ} \mathrm{C} / \mathrm{min}$ and nitrogen was used as fluidizing gas and found out that at $500^{\circ} \mathrm{C}$ without the presence of any catalyst the oil collection was $95 \%$. Doing pyrolysis of LDPE with Y-zeolite as catalyst the oil yield reduced to $85 \%$ and the gas yield increased. And without catalyst there were no residue left in the reactor. The main constituents of the product oil were aliphatic hydrocarbons. The gas obtained was passed through secondary container which was filled with catalyst Y-zeolite or ZSM-5 to obtain liquid oil. By passing through catalyst increased the aromatic content of oil obtained. Using Y-zeolite increased the aromatic content of oil than using ZSM-5 because of the fact that Y-zeolite has larger pores than ZSM-5. The pore diameter is an important factor in determining the product quality. The pore diameter of ZSM-5 and Y-zeolite is 5.5 $\mathrm{nm}$ and $7.4 \mathrm{~nm}$ respectively. On the other hand Jasmin sha et al (2004)[7] used different catalysts such as silica, calcium carbide, alumina, magnesium oxide, zinc oxide for the thermal degradation for LDPE in the temperature range of 200-400 ${ }^{\circ} \mathrm{C}$. Of which silica and calcium carbide were found effective and economical. By using calcium carbide as catalyst reduced the reaction time and the usage of silica resulted in better yield of liquid product oil. A maximum liquid oil yield of $79.81 \mathrm{wt} \%$ was obtained while using silica as catalyst at a low temperature of $350{ }^{\circ} \mathrm{C}$. J. Shah et al (2005)[8] also experimented on LDPE using lead sulfide as catalyst. The process was carried out in a batch reactor at atmospheric pressure. The conversion rate was almost $100 \%$. Since the char formation is negligible the catalyst can be used repeatedly. The products obtained were olefin and paraffinhydrocarbon compounds. The density of the obtained oil were $0.81 \mathrm{~g} / \mathrm{ml}$, kinematic viscosity were 3.27 $\mathrm{mm}^{2} / \mathrm{sec}$ and the calorific value $41 \mathrm{MJ} / \mathrm{kg}$.

Table 2: Liquid oil yield on the basis of type of catalyst used [7]

\begin{tabular}{|l|l|l|}
\hline Parameter & Calcium carbide & Silica \\
\hline Temperature & 350 & 350 \\
\hline Catalyst $(\mathrm{g})$ & 1 & 1 \\
\hline Time $(\mathrm{min})$ & 60 & 180 \\
\hline Liquid oil $(\%)$ & 70.37 & 79.81 \\
\hline
\end{tabular}

Marcela et al (2008) [9] also done LDPE in a batch reactor and got a liquid oil yield of $93.1 \%$ from LDPE with zero residue left in the reactor at a lower heating rate of $5^{\circ} \mathrm{C} / \mathrm{min}$. The liquid and gas fractions were mainly composed of 1olefins and n-paraffins. The carbon number ranged from 140. While using HZSM-5 as catalyst the gaseous product produced increased considerably and the liquid fraction decreased. 
Table 3: Weight fraction analysis of LDPE with and without catalysts [8]

\begin{tabular}{|l|l|l|l|}
\hline Weight fraction $(\%)$ & LDPE & LDPE (HZSM5-) & LDPE (HUSY) \\
\hline n-Paraffins & 33.4 & 4.4 & 23.4 \\
\hline iso-Paraffins & 0.0 & 4.1 & 11.4 \\
\hline 1-Olefins & 51.0 & 8.6 & 16.4 \\
\hline Olefins & 15.6 & 30.8 & 17.5 \\
\hline Aromatics & 0.0 & 52.1 & 31.3 \\
\hline
\end{tabular}

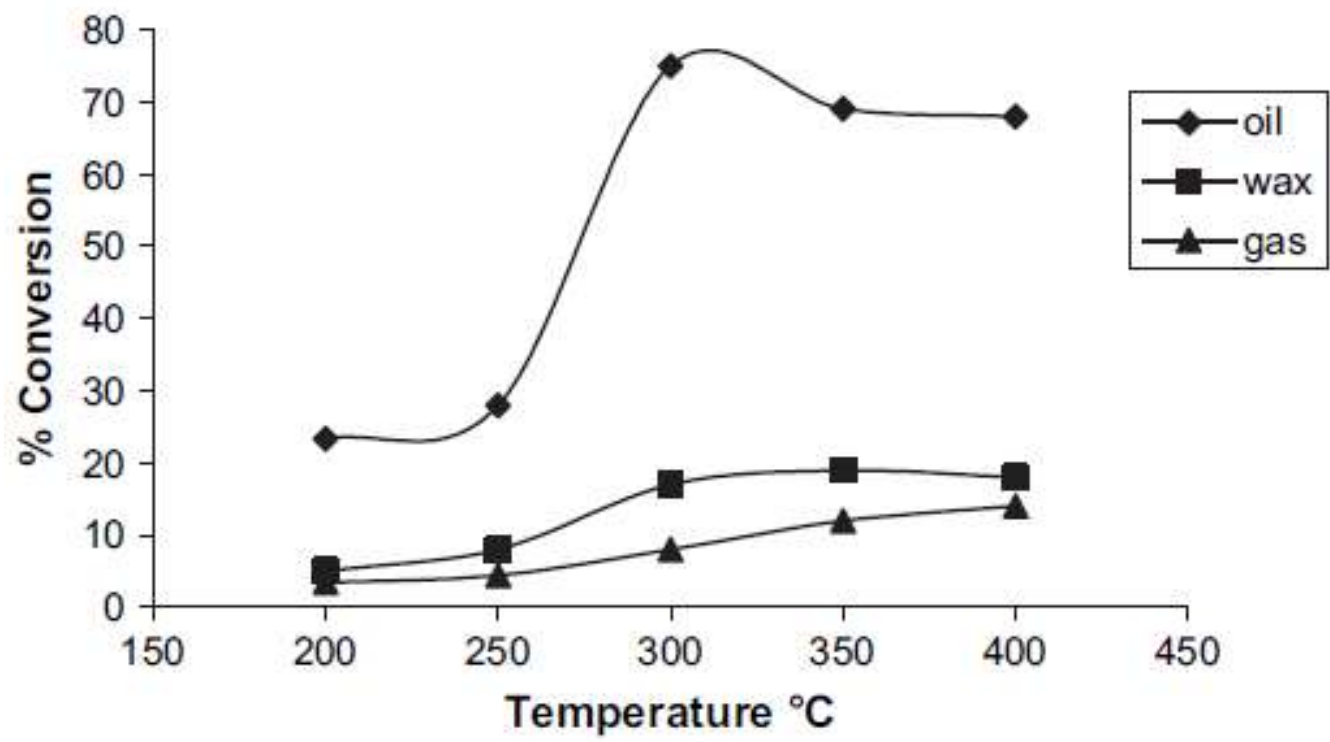

Fig 1: Product analysis of LDPE [8]

Polypropylene is a polymer formed from the propylene monomer. Unlike polyethylene it has a high melting point and can be combined with other substances like rubber to improve its characteristics. It can be molded to any shapes easily.PP contributes highest share in the municipal waste as high as $24.3 \%$ [Michael pa] [10]. PP has many uses such as thermal jackets, car bumpers, loud speakers, ropes, various laboratory appliances... The heavy consumption makes the PP one of the largest components of municipal solid waste. Since plastic waste contains exorbitant content of PP makes it an interesting subject for researchers.

In the study conducted by Su-Hwa Jung et al (2010) [11] of PP on a fluidized bed pyrolysis reactor, they summarized that $43.1 \%$ of oil obtained at $668 \mathrm{C}$.

Ahmed et al (2014) [12]studied the pyrolysis of PP on a steel reactor in the temperature range of $250-400^{\circ} \mathrm{C}$ and obtained a maximum liquid fraction of $69.82 \%$ at $300^{\circ} \mathrm{C}$ and a total yield of $98.66 \%$ with a solid residue as low as $1.34 \%$ left in the reactor. After $300^{\circ} \mathrm{C}$ the liquid fraction were decreasing. The density of PP oil obtained were $0.86 \mathrm{~g} / \mathrm{cm}^{3}$ at $15^{\circ} \mathrm{C}$. The kinematic viscosity at $40^{\circ} \mathrm{C}$ were $4.09 \mathrm{~mm}^{2} / \mathrm{sec}$
Polystyrene is known to as the transparent thermoplastic is formed by polymerization of styrene monomer. It has been used in many applications such as packaging of food and medicines, electrical appliances, toy making... Researchers are interested in the pyrolysis of PS due to the high yield.Yirong Liu et al (1999)[13] studied the pyrolysis of PS at temperatures ranges of $450-700 \mathrm{C}$ in a fluidized bed reactor and got a maximum yield of $78.7 \mathrm{wt} \%$ at $600 \mathrm{C}$. Further increase in temperature leads to reduction in yield. One of the disadvantages of polymerization of PS were at lower temperature PS melted and stick to the reactor surfaces causes coke deposits on the reactor wallg madras et.al (1997) [14] This hindered the efficient formation of styrene monomer. Melting takes place at a lower temperature of $200 \mathrm{C}$. The products obtained were styrene monomer, dimer, trimer, benzene, and toluene. Lowboiling point(less than $200^{\circ} \mathrm{C}$ ) was also obtained by vacuum distillation of product oil which is similar to boiling point of gasoline. So it is important to develop a reactor with high heat transfer rate. Jude et al (2009) utilized a batch pyrolysis reactor in the temperature range of 300-500C and obtained a maximum oil yield of $97 \mathrm{wt} \%$ at $425 \mathrm{C}$. The oil yield tends to decrease on further increase in temperature. 


\section{CONCLUSION}

From the studies discussed above we can conclude that pyrolysis of waste plastic produces wide range of hydrocarbons. The product obtained is based on type of plastic, temperature, residence time, presence of catalyst... Of which PET produces very less liquid oil and more gaseous fractions and hence pyrolysis of PET for obtaining liquid oil is not economical. The product obtained for PET was oligomer. It can be understood from above mentioned studies higher operating temperatures increases gas yield and decreases liquid oil yield. By analyzing liquid oils of various plastics the carbon length for most of them were in the range 10-50. Heating values of HDPE, LDPE, PS and PP were in between 30-45 MJ/kg. Using Y-zeolite as catalyst in pyrolysis of LDPE increased the aromatic content of product oil which is good for production of gasoline grade fuel. Also the presence of catalyst reduces the temperature for thermal degradation of plastics. The pore size of catalyst is an important factor in determining the quality of fuel. Using Y-zeolite as catalyst increased the oil yield than using ZSM-5 as catalyst. Using Lead-Sulfide as catalyst on LDPE increases the product yield to $100 \%$ with zero char production. The liquid oil obtained shows physical and chemical properties of commercial kerosene and diesel. So it has the potential to use as fuel for energy utilization. The pore size of catalyst is an important factor in determining the quality of fuel. Using Y-zeolite as catalyst increased the oil yield than using ZSM-5 as catalyst. Using Lead-Sulfide as catalyst on LDPE increases the product yield to $100 \%$ with zero char production. The liquid oil obtained shows physical and chemical properties of commercial kerosene and diesel. So it has the potential to use as fuel for energy utilization.

Table 3: Oil yield of PET, PS, LDPE, HDPE, PP at various temperatures

\begin{tabular}{|l|l|l|l|l|l|}
\hline \multirow{2}{*}{ Temperature ${ }^{\circ} \mathrm{C}$} & \multicolumn{5}{|l|}{ Oil yield percentage } \\
\cline { 2 - 6 } & PET & PS & LDPE & PP & HDPE \\
\hline 300 & 0 & 65.71 & 78.39 & 79.62 & 88.54 \\
\hline 400 & 0 & 66.45 & 76.58 & 78.70 & 87.81 \\
\hline 500 & 0 & 67.23 & 69.19 & 78.58 & 87.62 \\
\hline 600 & 0 & 64.85 & 73.20 & 77.50 & 87.55 \\
\hline
\end{tabular}

\section{REFERENCES}

[1] Toshiaki Yoshiokaa, Guido Grauseb, Christian Egerb,WalterKaminskyb, AkitsuguOkuwakic, Pyrolysis of poly(ethylene terephthalate) in a fluidized bed plant, Polymer Degradation and Stability 86 (2004) 499-504.

[2] MoinuddinSarker, AminulKabir, Mohammad MamunorRashid,MohammedMolla, and A. S. M. Din Mohammad, Waste Polyethylene Terephthalate (PETE-1) Conversion into Liquid Fuel, Journal of Fundamentals of Renewable Energy and Applications Vol. 1 (2011), Article ID R101202, 5 pages

[3] Imtiaz Ahmad, M. Ismail Khan , Hizbullah Khan , M. Ishaq, Razia Tariq, KashifGul\&Waqas Ahmad (2014): Pyrolysis Study of Polypropylene and Polyethylene in to Premium Oil Products, International Journal of Green Energy, DOI: 10.1080/15435075.2014.880146

[4] N. Miskolczi, L. Bartha, G. Deak, B. Jover, D. Kallo, Thermal and thermo-catalytic degradation of highdensity-polyethylene waste. J. Anal. Appl. Pyrolysis 72, (2004) 235-242.

[5] Weibing Ding, Jing Liang, Larry L. Anderson, Thermal and catalytic degradation of high density polyethylene and commingled post-consumer plastic waste, Fuel Processing Technology 51 (1997) 47-62

[6] R. Bagri, P.T. Williams, Catalytic pyrolysis of polyethylene, J. Anal. Appl. Pyrolysis 63 (2002) 2941.

[7] Jasmin Shah, M. Rasul Jan , FazalMabood, Farah Jabeen, Catalytic pyrolysis of LDPE leads to valuable resource recovery and reduction of waste problems, Energy Conversion and Management 51 (2010) 2791-2801.

[8] Jasmin Shah, M. Rasul Jan, ZahidHussain, Catalytic pyrolysis of low-density polyethylene with lead sulfide into fuel oil,Polymer Degradation and Stability 87 (2005) 329-333.

[9] Marcilla , M.I. Beltra n, R. Navarro, Thermal and catalytic pyrolysis of polyethylene over HZSM5 and HUSY zeolites in a batch reactor under dynamic conditions, Applied Catalysis B: Environmental 86 (2009) 78-86

[10] P. A. Michael, "Plastic waste total in MSW," Society of the Plastic Industry, 2010.

[11] Su-Hwa Jung, Min-Hwan Cho, Bo-Sung Kang, JooSik Kim, Pyrolysis of a fraction of waste polypropylene and polyethylene for the recovery of BTX aromatics using a fluidized bed reactor, Fuel Processing Technology 91 (2010) 277-284

[12] Imtiaz Ahmad, M. Ismail Khan , Hizbullah Khan , M. Ishaq , Razia Tariq , KashifGul\&Waqas Ahmad (2014): Pyrolysis Study of Polypropylene and Polyethylene in to Premium Oil Products, International Journal of Green Energy

[13] Yirong Liu, JialinQian, Jianqiu Wang, Pyrolysis of polystyrene waste in a fluidized-bed reactor to obtain styrene monomer and gasoline fraction, Fuel Processing Technology 63 2000.45-55

[14] GiridharMadrasJ.M.SmithBenjaminJ.McCoy, Thermal degradation kinetics of polystyrene in solution, Polymer Degradation and StabilityVolume 58, Issues 1-2, 1997, Pages 131-138. 